\title{
Using an experimental model for the study of therapeutic touch ${ }^{1}$
}

\author{
Daniella Soares dos Santos² \\ Ilda Estéfani Ribeiro Marta ${ }^{3}$ \\ Evelin Capellari Cárnio ${ }^{4}$ \\ Andreza Urba de Quadros ${ }^{5}$ \\ Thiago Mattar Cunha ${ }^{6}$ \\ Emilia Campos de Carvalho ${ }^{7}$
}

\begin{abstract}
Objective: to verify whether the Paw Edema Model can be used in investigations about the effects of Therapeutic Touch on inflammation by measuring the variables pain, edema and neutrophil migration. Method: this is a pilot and experimental study, involving ten male mice of the same genetic strain and divided into experimental and control group, submitted to the chemical induction of local inflammation in the right back paw. The experimental group received a daily administration of Therapeutic Touch for 15 minutes during three days. Results: the data showed statistically significant differences in the nociceptive threshold and in the paw circumference of the animals from the experimental group on the second day of the experiment. Conclusion: the experiment model involving animals can contribute to study the effects of Therapeutic Touch on inflammation, and adjustments are suggested in the treatment duration, number of sessions and experiment duration.
\end{abstract}

Descriptors: Therapeutic Touch; Nursing; Inflammation.

\footnotetext{
${ }^{1}$ Paper extracted from doctoral dissertation "Avaliação do efeito anti-inflamatório do Toque Terapêutico no modelo experimental de edema de pata induzido por Adjuvante Completo de Freund em camundongos" presented to Programa Interunidades de Pós-graduação em Enfermagem, Escola de Enfermagem, Universidade de São Paulo, São Paulo, SP, Brazil and Escola de Enfermagem de Ribeirão Preto, Universidade de São Paulo, WHO Collaborating Centre for Nursing Research Development, Ribeirão Preto, SP, Brazil.

2 PhD, Adjunct Professor, Departamento de Enfermagem, Universidade de Brasília, Brasília, DF, Brazil.

${ }^{3}$ PhD, Adjunct Professor, Departamento de Enfermagem, Universidade Federal do Mato Grosso do Sul, Três Lagoas, MS, Brazil.

${ }^{4}$ PhD, Associate Professor, Escola de Enfermagem de Ribeirão Preto, Universidade de São Paulo, WHO Collaborating Centre for Nursing Research Development, Ribeirão Preto, SP, Brazil.

${ }^{5}$ Master's student, Faculdade de Medicina de Ribeirão Preto, Universidade de São Paulo, Ribeirão Preto, SP, Brazil.

${ }^{6} \mathrm{PhD}$, Professor, Faculdade de Medicina de Ribeirão Preto, Universidade de São Paulo, Ribeirão Preto, SP, Brazil.

7 PhD, Full Professor, Escola de Enfermagem de Ribeirão Preto, Universidade de São Paulo, WHO Collaborating Centre for Nursing Research Development, Ribeirão Preto, SP, Brazil.
}

Corresponding Author:

Daniella Soares dos Santos

Universidade de Brasília. Departamento de Enfermagem

Avenida L3 Norte s/n

Bairro: Asa Norte

CEP: 70910-900, Brasília, DF, Brasil

E-mail: dani_santosbsb@hotmail.com 


\section{Introduction}

Therapeutic Touch (TT) is an integrative therapy based on the ancient technique of laying on hands and has been used by nurses since the 1970s to treat patients with various clinical conditions. It is based on the multidimensionality of the human being and on the widely accepted concept in Eastern tradition that an illness is the manifestation in the physical body of the imbalance in its energy field.

After discovering the therapeutic potential of $\Pi$, the nurse Dolores Krieger started a series of scientific studies that resulted in the process' systemization in four stages: Centralization; Assessment of the patient's energy field; Treatment or modulation of the energetic field and Reassessment of the energy field(1).

The $T$ consists of skills learned to direct and modulate human energies in a conscious and sensitive manner(1). Its diffusion, especially in the United States, where it is part of the curriculum in several Nursing schools, has contributed to a growing scientific and academic interest in its effects.

The research initiated by Krieger showed amazing results, which attracted the interest of academics from various fields. Currently, studies have been directed at investigating its physiological, psychological and behavioral effects, as well as the action mechanism involved in the research findings ${ }^{(2)}$.

Currently, the $\Pi \mathrm{T}$ is considered an important care strategy used by nursing professionals. Some of the benefits resulting from this therapy and reported in the literature are: improved sleep patterns in people with non-oncologic chronic pain ${ }^{(3)}$, changing patterns of vital signals in health people ${ }^{(4)}$, reduction of agitation in the elderly with Alzheimer(5) and dementia(6), change in hemoglobin and hematocrit levels ${ }^{(7)}$, effect on the immune response ${ }^{(8)}$, change in plasma concentration of nitric oxide ${ }^{(9)}$ and increased sensitivity ${ }^{(10)}$.

Although the literature points out the benefits of using $\Pi$, a recent systematic review of clinical trials involving interventions showed difficulties in the replication of the $\pi$ results, due to the lack of accurate description of the manner in which it was implemented, the concomitant use of other interventions, the lack of standardization in the administration of the therapy and the inclusion of participants with different types of illnesses in the same study ${ }^{(11)}$.

Amongst the studied variables involving the use of $\pi$ in clinics, pain is one the main. Several studies show the benefits of $\pi$ in the treatment of pain ${ }^{(12-16)}$, but there is a lack of studies explaining the physiological mechanisms responsible for the results, in particular due to the wide variety of clinical conditions that trigger pain conditions and to the methodological difficulties of control, sample homogeneity and results generalization.

These problems led to the investigation of the $\pi$ action on a clinical condition in which the pathophysiological mechanisms are already widely described, that is, the inflammation, using a method that permits replicating the results.

Inflammation is a nonspecific local reaction that occurs in tissues that suffer aggressions and is characterized by a number of changes, aimed at limiting the aggressive effects(17).

The causes of inflammation are varied and generally result from an immunological response to infectious microorganisms, trauma, surgery, caustic chemicals, extreme cold or heat, besides ischemic lesions in body tissues $^{(18)}$.

Changes resulting from an inflammatory response may be local or systemic and, in its acute form, the inflammatory response is characterized by a quick start, followed by the resolution of the lesion and tissue changes that occur in a short period of time(18).

The acute inflammation are characterized by exudative events, due to the changes in vascular permeability, which contribute to the accumulation of other substances and cells such as fibrin, resulting from the interaction between plasma components and tissue factors, leukocytes especially neutrophils and erythrocytes $^{(17)}$.

One of the most significant local changes seen in the inflammatory reaction is the migration of neutrophils of the circulating blood. These cells have a decisive role in the fight against harmful stimuli, both for its phagocytic function and the production of chemical mediators that will act towards recruiting other defense cells ${ }^{(19-20)}$.

The study of inflammatory reaction requires the use of different substances from antigens which are able to boost the activation of $\mathrm{T}$ lymphocytes, besides promoting the accumulation of cells carrying antigens that prolong the immunological response, which has been made possible with the use of adjuvants(21).

For this purpose, the adjuvants may be alum, aluminum hydroxide, aluminum phosphate, lyposaccharides of negative gram bacteria and oil emulsions. Concerning the oil adjuvant category, they can be classified into complete and incomplete. In the composition of complete adjuvants, mineral oil is added to ensure the action of deposit, formation of granulomas 
rich in macrophages and immune-competent cells, besides the distance action on the lymphoid organs such as spleen and lymph nodes(22).

When administered into an animal's paw via intraplantar injection, the Freund Complete Adjuvant (FCA) induces a stable local inflammatory response with severe pain around the injected area and, for this reason, the inflammatory model of paw edema induced via FCA has been used in studies involving this type of condition(23), also to test the effect of therapies like Acupuncture(24) $^{(24)}$ this type of pain.

Based on the above, this study was aimed at verifying whether the paw edema model can be used in research about the effects of Therapeutic Touch on inflammatory responses by measuring the variables pain, edema and neutrophil migration.

\section{Method}

\section{Design and Sampling}

This is a pilot study carried out at the Pharmacology Laboratory, University of São Paulo at Ribeirão Preto Medical School, in May 2011.

The sample was composed of 10 male mice of the C57BL/6 strain, weighing about 20 grams each and belonging to the vivarium of the above mentioned university, which were divided into two groups: Experimental Group $(\mathrm{FCA}+\mathrm{TT})$ and Control Group (FCA).

\section{Administration of Therapeutic Touch}

Tा was administered to animals from the experimental group ( $\mathrm{FCA}+\mathrm{T})$ for 15 minutes, once a day for three days at around $2 \mathrm{pm}$, by a nurse with experience using this method on patients with chronic pain.

For the administration of $\pi$, the animals from the experimental group $(\mathrm{FCA}+\mathrm{TT})$ were kept in a PVC box measuring $30 \mathrm{~cm}$ (horizontally) by $18 \mathrm{~cm}$ (vertically) by $14 \mathrm{~cm}$ (height) on a bench, in a reserved room in order to ensure concentration on the part of the therapist. Prior to the treatment, the animals were kept in this box for 30 minutes to adapt to it. During the application, the nurse stayed next to the box and placed her hands above the animals, without physical contact.

\section{Preparation of the animals and data measurement}

The induction of paw edema was performed through the intraplantar administration of $10 \mu \mathrm{L}$ of
Freund Complete Adjuvant (FCA), in the right back paw of ten animals.

The assessment of mechanic hypernociception was performed by a trained researcher by using the previously described method of increased pressure in the paw of rats and mice ${ }^{(25)}$. For this, an electronic anesthesiometer (Model 1601C, Life Science Instruments, California, USA) was used, consisting of a pressure transducer connected by a cable to a digital power detector expressed in grams. The probe Universal Tips $10 \mathrm{~mL}$ (T-300, Axygen) was adapted to the transducer and directly stimulated the paw of the animal. The probe was applied in straight angles to the central area of the back paw of the animal with gradually increasing pressure, which caused a typical flexion response with its withdrawal, when the stimulus was discontinued.

Hypernociception intensity was quantified as the variation of pressure ( $D$ reaction in grams) obtained by subtracting the value observed before the experimental procedure from the value of the reaction after TT administration. During the measurement, the animals were kept in acrylic boxes of $12 \times 100$ by $17 \mathrm{~cm}$ (height) and floors formed by a mesh net of about $5 \mathrm{~mm}^{2}$, consisting of non-malleable wire of $1 \mathrm{~mm}$ diameter, maintained at about $30 \mathrm{~cm}$ from a bench surface for stimulation of the animals' back paws.

In order to minimize stress, the animals were kept resting in these boxes for about 40 minutes before the measurement of the nociceptive threshold.

The volume measurement of the paws was performed with the use of a digital caliper of the Marberg brand, 0 to $200 \mathrm{~mm}$. The edema area was calculated by multiplying the measurements of the width and height of the paw by the value of $\Pi$ (3.14159265), before and after the administration of $\pi$.

Prior to the administration of the FCA, all animals underwent measurement of the volumes of the right back paws and of the nociceptive threshold (Baseline Data). The contralateral paws (called Saline) of the animals from the control group were also measured for individual control. Once the administration of $\pi$ began in the experimental group ( $\mathrm{FCA}+\mathrm{TT})$, all measures were taken before and after the administration, on the first, second and fourth days of the experiment. There was no contact between the two groups of animals. All administrations were carried out in both groups in order to ensure consistency to the method.

Neutrophil migration was measured indirectly by the activity of the enzyme myeloperoxidase (MPO), conducted through the kinetic method. After euthanizing 
the animals by spinal dislocation, followed by bleeding through partial decapitation, the right back paws of all animals were collected, cut into small pieces and weighed after removal of bones and ligaments. The samples were stored in eppendorf containing $500 \mu \mathrm{L}$ of buffer 2, previously weighed, identified and kept in an ice bath at $-20^{\circ} \mathrm{C}$. The pieces of the paw were homogenized three times in polytron and centrifuged at $3000 \mathrm{rpm}$ for 15 minutes at $4^{\circ} \mathrm{C}$. This procedure was also performed on the contralateral paws of animals in the control group (FCA).

It is important to note that, for routine treatment, each group of animals was kept in an acrylic box with dimensions of $30 \mathrm{~cm}$ (horizontal) $\times 18 \mathrm{~cm}$ (vertical) $\times 14 \mathrm{~cm}$ (height), in an acclimatized room, at temperatures between 20 and $22^{\circ} \mathrm{C}$ with light/ dark cycles of $12 / 12$ hours and receiving food and water ad libitum, in the vivarium of the Pharmacology Department of the mentioned University. The routine care of the animals and administration procedures were performed in accordance with the The Ethical Principles in Animal Research, adopted by Colegio Brasileiro de Experimentação Animal (COBEA).

\section{Statistical Analysis}

Data analysis was carried out using the software PRISM $^{\circledR}$ 5. The data are presented according to the average \pm average standard deviation (EPM) for absolute values. The differences between the groups were analyzed through a one-way ANOVA Test, followed by Bonferroni's multiple comparison test. For the analysis of variance homogeneity, the Bartlett Test was used. Values of $p<0.05$ were considered significant.

\section{Ethical Aspects}

The study was approved by the Ethics in Animal Experiments Committee (CETEA) of the University of São Paulo at Ribeirao Preto Medical School, under registration number $16 / 2011$.

\section{Results}

Immediately after the administration of FCA, its effectiveness in encouraging an inflammatory response was observed, verified by reducing the nociceptive threshold of the animals after the drug administration and compared with the values obtained before its administration (Baseline). The values were obtained from measurements at different time intervals (first to fourth day) and expressed in averages \pm EPM (Average Standard Deviation). The analysis revealed a significant reduction $(p<0.05)$ in the nociceptive threshold of the paws treated with the drug (ANOVA followed by Bonferroni Test) (Figure 1). The same effect was not seen in relation to the paws treated with saline solution, which maintained a high nociceptive threshold (Figure 2).

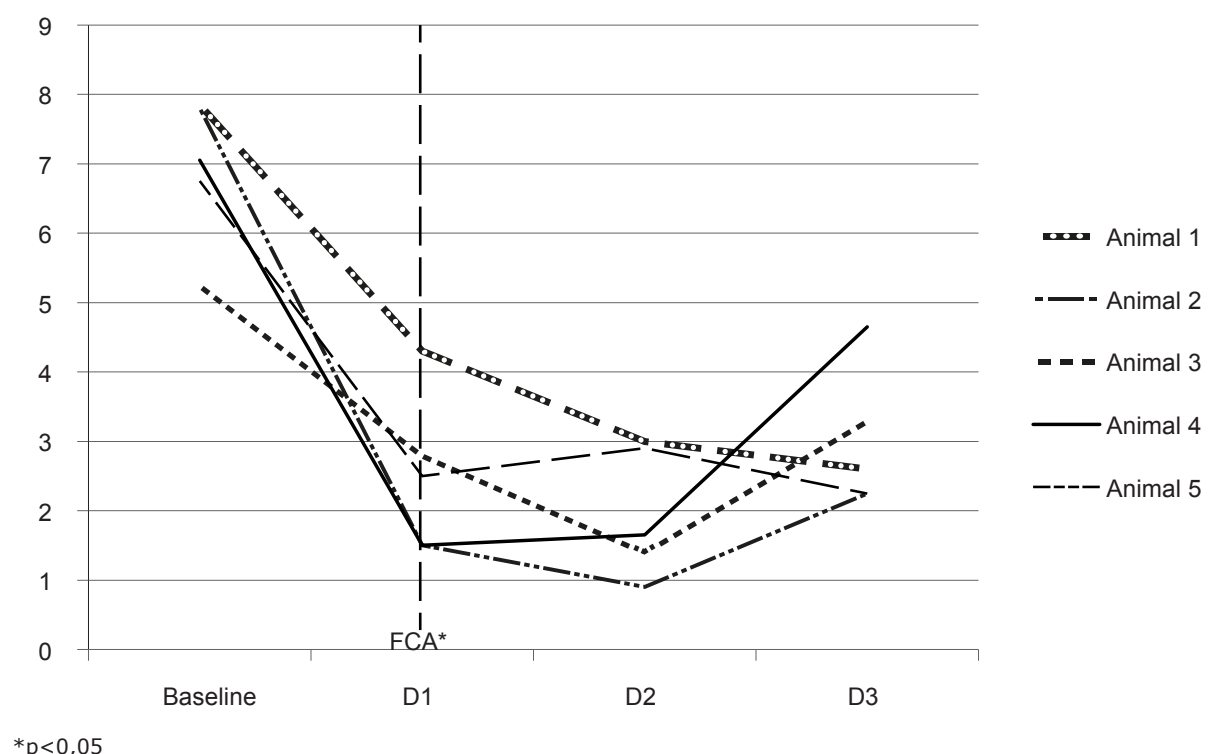

$* \mathrm{p}<0,05$

Figure 1 - Temporal evolution of the variation in the mechanical nociceptive threshold in the paws of animals from the Control Group treated with FCA. Ribeirão Preto, SP, Brazil, 2011 


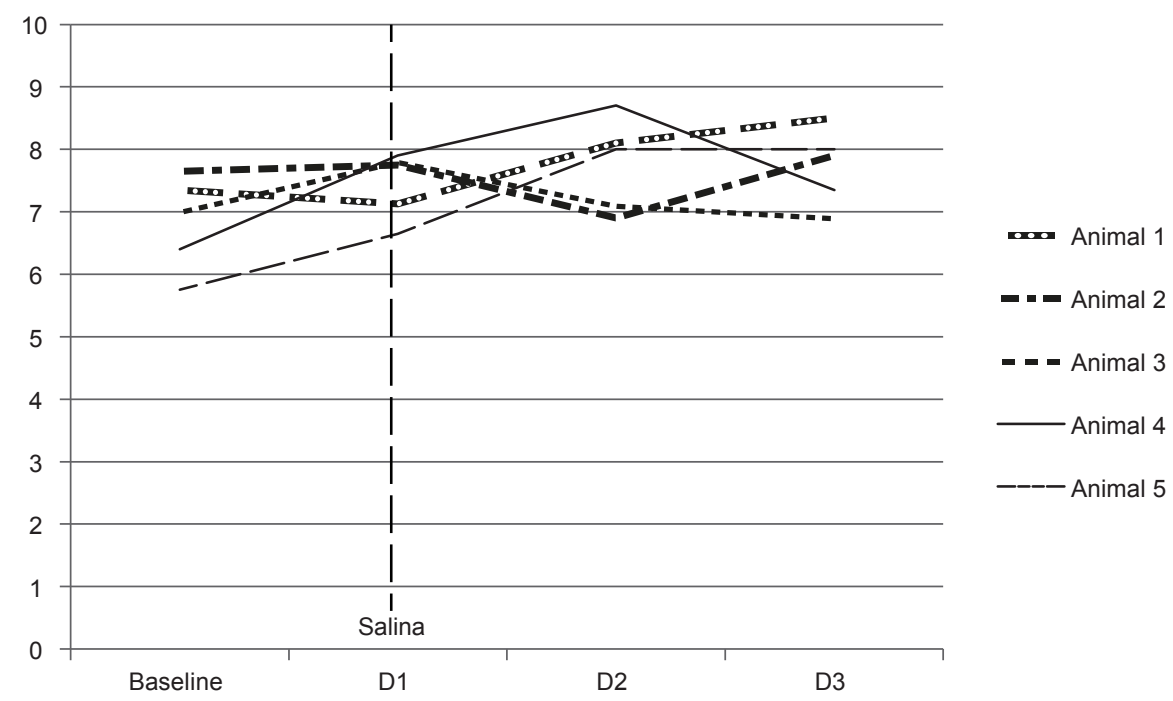

Figure 2 - Temporal evolution of the variation in mechanical nociceptive threshold in the paws of animals from the Control Group treated with Saline Solution. Ribeirão Preto, SP, Brazil, 2011

Once the Experimental Group treatment with $\Pi$ was started, the assessment of its effect on the pain revealed a statistically significant increase in nociceptive threshold (increased mechanical threshold and, thus, reduction of pain) of the animals from the experimental group $(\mathrm{FCA}+\mathrm{TT})$ on the second day of the experiment and in the measurement taken before the intervention $(* p<0.05)$. Such effect was not seen on the other days or in the animals from the control group (FCA) (Figure 3).

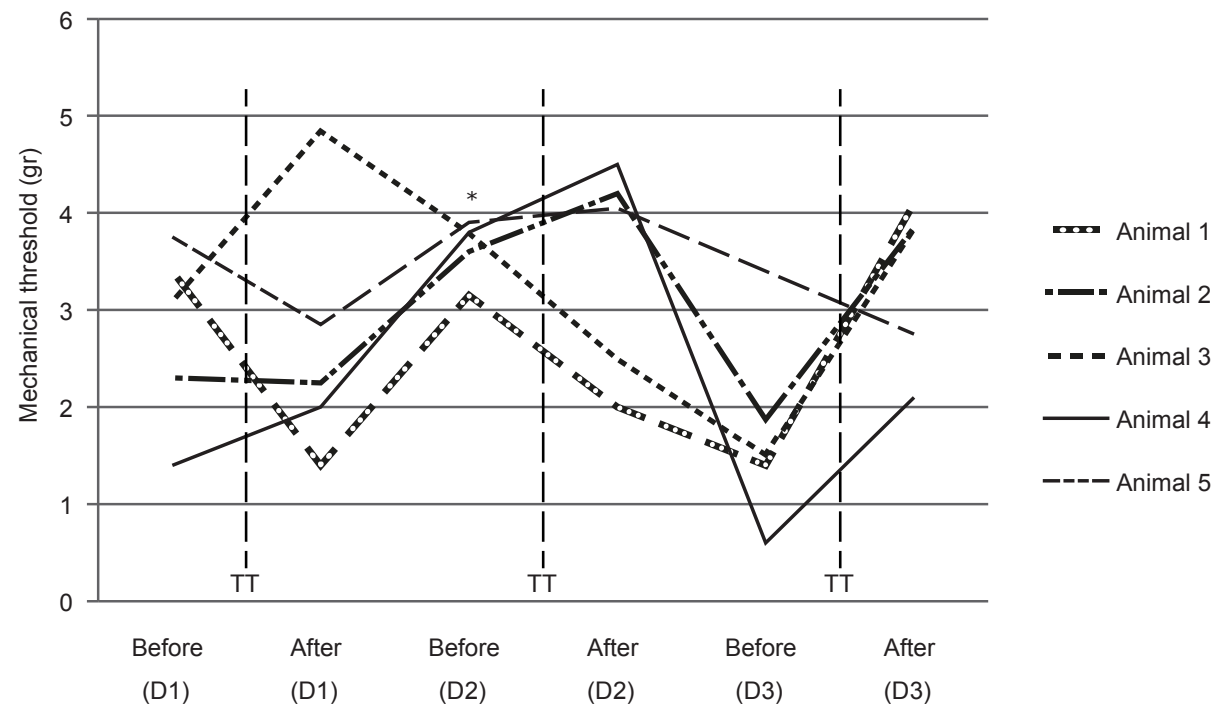

$* \mathrm{p}<0,05$

Figure 3 - Assessment of the effect of $T$ on the nociceptive threshold of animals after induction of paw edema in the experimental group (FCA+TT). Ribeirão Preto, SP, Brazil, 2011 
The administration of FCA caused a statistically significant increase in paw volume of the animals from both groups $(p<0.05)$. There was a significant increase in paw volume of the animals from the Experimental Group (treated with $\Pi$ ) on the second day of the experiment $(p<0.05)$. Such effect was not seen in the control group animals, nor maintained until the end of the experiment.
At the end of the experiment, the euthanasia of the animals and the assessment of neutrophil migration were carried out and measured by MPO trial. Statistical analysis showed that the experimental group ( $F C A+\pi$ ) had reduced neutrophil migration when compared to the control group (FCA), but this was not statistically significant $(p=0.66)$ (Figure 4$)$.

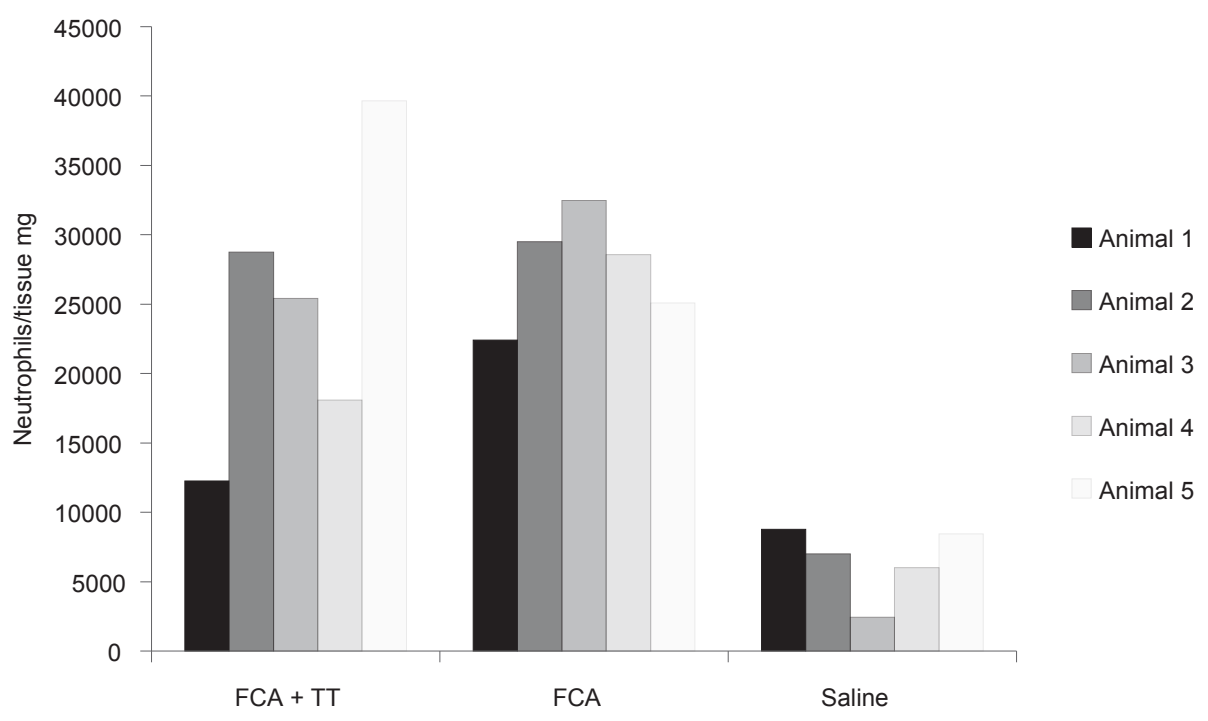

Figure 4 - Results of the administration of $\Pi T$ on neutrophil migration in the animals from the experimental group $(F C A+T T)$, compared to the animals from the control group (FCA). Ribeirão Preto, SP, Brazil, 2011

\section{Discussion}

The benefits of practices, some of them ancient, which preserve or recover health and maintain people's quality of life are known in the literature ${ }^{(25)}$. The search for recognition of the benefits and indication of the usefulness of these integrative therapies in the treatment of various clinical issues has led researchers to employ methodologies that encourage the control and allow the investigation of their action mechanisms. In this sense, the paw edema model induced by FCA has been used in studies that involve interventions for pain and its effects on physiological variables, using methods and control that cannot be applied to studies that involve human beings(24,26). This study was directed to the effect of $\Pi T$ intervention on manifestations of pain, edema and neutrophil migration, which are present in local inflammation.

The induction of local inflammation, after injection of FCA, into the right back paws of animals, could be noted by the reduction of the mechanical nociceptive threshold and increased paw volume in animals of both groups (Figures 1 and 2). Similarly to those found in the literature(24), these data confirm the acute inflammatory power of the drug and the relevance of its use in studies about $T$.

Although a significant reduction in the pain was noted on the second day of $T T$ administration, and taking into consideration that the inflammatory effect was maintained throughout the period of the experiment, it can be highlighted that minimization of the animals handling and extension in the duration of the experiment should be considered in further studies.

Regarding the edema increase, which was only seen on the second day of the experiment, it is believed that the small sample size used could have affected these results, given the character of a pilot study and possible difficulties resulting from this technique.

The third variable investigated in this study was the neutrophil migration, assessed by MPO trial, which 
is a hemoprotein located in the neutrophils' azurophil granules and used as biochemical marker for indirect measurement of neutrophil infiltration into the tissues. The reduction in the concentration of MPO reflects a decrease in the intensity of the inflammatory activity ${ }^{(20)}$.

The MPO dosage revealed no statistically significant reduction in neutrophil migration between the groups $(p=0.66)$ (Figure 5$)$. Considering the character of a pilot study, it is believed that adjusts need to be made concerning the method used for measuring this variable.

Studies carried out to determine the effect of $T T$ on cell activity in human beings do not suggest the minimum intervention needed to obtain significant effects. In the present study, taking into consideration there was a difference between the groups, although without statistical significance, it is believed that the comparison of different intervention periods, number of daily sessions and total duration time of the experiment may be relevant.

\section{Conclusion}

The results of this study suggest that the paw edema model can be used to investigate the effect of $\Pi$ on inflammation, measured through pain, edema and neutrophils migration.

Methodological adjustments in relation to the reduction of animal handling, by measuring the variables only after administration of $\pi$, increase in sample size and the duration of the therapy prior to MPO trial may benefit further investigations.

The importance of studies involving animals should be highlighted, in particular those findings that contribute to the construction of further randomized clinical experiments in a clinical nursing environment, with the purpose of verifying the results of $T T$ intervention on the expression of variables like pain, edema and biological markers in patients.

\section{References}

1. Krieger D. O toque terapêutico. 9th. ed. São Paulo: Cultrix; 1999. 248 p.

2. Vasques CI, Santos DS, Carvalho EC. Tendências da pesquisa envolvendo o uso do Toque Terapêutico como uma estratégia de enfermagem. Acta Paul Enferm. 2011; 24(5):712-4.

3. Marta IER, Baldan SS, Berton PM, Silva MJP. The effectiveness or therapeutic touch on pain, depression and sleep in patients with chronic pain: clinical trial. Rev Esc Enferm USP. 2010;44(4):1100-6.
4. Maville JA, Bowen JE, Benham G. Effect of healing touch on stress perception and biological correlats. Holist Nurs Pract. 2008;22(2):103-10.

5. Hawranik $P$, Johnston $P$, Deatrich J. Therapeutic touch and agitation in individuals with Alzheimer's disease. Western J Nurs Res. 2008;30(4):417-34.

6. Wang $\mathrm{KL}$, Hermann C. Pilot study to test the effectiveness of healing touch on agitation in people with dementia. Geriatric Nurs. 2006;27(1):34-40.

7. Movaffaghi Z, Hasanpoor M, Farsi M, Hooshmand P, Abrishami F. Effects of Therapeutic Touch on Blood Hemoglobin and Hematocrit Level. J Holist Nurs. 2006;24(1):41-8.

8. Wilkinson DS, Knox PL, Chatman JE, Johnson $T L$, Barbour N, Myles Y, Reel A. The clinical effectiveness of healing touch. J Alternative Complementary Med. 2002;8(1):33-47.

9. Lafraniere KD, Mutus $B$, Cameron S, Tannous M, Giannotti M, Abu-zahra $H$, et al. Effects of Therapeutic Touch on biochemical and mood indicators in women. J Altern Complement Med. 1999;5(4):367-70.

10. Silva MJP, Belasco Junior, D. Ensinando o toque terapêutico: relato de uma experiência. Rev. Latino-Am. Enfermagem. [periódico na Internet]. 1996; 4 (spe):91100. [acesso 29 jul 2012]. Disponível em: http://dx.doi. org/10.1590/S0104-11691996000700010.

11. Anderson JG, Taylor AG. Effects of Healing Touch in Clinical Practice: A systematic review of randomizer clinical trials. J Holist Nurs. 2011;29(3):221-8.

12. Eckes Peck SD. The effectiveness of therapeutic touch for decreasing pain in elders with degenerative arthritis. J Holist Nurs. 1997;15(2):176-98.

13. Gordon A, Merenstein JH, D'amico F, Hudgens D. The effects of therapeutic touch on patients with osteoarthritis of the knee. J Fam Pract. 1998;47(4):271-7.

14. Denison D. Touch de pain away. Holist Nusr Pract. 2004; 18:142-51.

15. Blankfield RP, Sulzmenn C, Fradely LG, Tapolyai AA, Zyzansky SJ. Therapeutic Touch in the treatment of carpal tunnel syndrome. J Am Board Fam Pract. 2001;14:335-42. 16. Turner JG, Clark AJ, Gauthier D, Williams M. The effect of Therapeutic Touch on pain and anxiety in burn patients. J Adv Nurs. 1998;28(1):10-20.

17. Montenegro MR, Fechio D. Inflamação: conceitos gerais e inflamação aguda. In: Montenegro MR, Fechio D. Patologia Processos Gerais. São Paulo (SP): Atheneu; 2006. p. 109-28.

18. Sommer C. Imunidade e Inflamação. In: Porth CM, Kunert MP. Fisiopatologia. Rio de Janeiro (RJ): Guanabara Koogan; 2002. p. 338. 
19. Coelho CF. Avaliação do efeito anti-inflamatório do óxido nítrico administrado por via inalatória no modelo experimental de edema de pata induzido por carragenina em camundongos. [tese na Internet]. São Paulo (SP): Instituto de Ciências Biomédicas da Universidade de São Paulo; 2009. 101 p. [acesso 10 abr 2011]. Disponível em http://www.teses.usp.br/teses/disponiveis/42/42136/ tde-26012010-115811/pt-br.php

20. Salvemini D, Wang ZQ, Wyatt PS, Bourdon DM, Marino MH, Manning PT, Currie MG. Nitric oxide: a key mediator in the early late phase of carrageenan-induced rat paw inflammation. Br J Pharmacol. 1996;118:829-38. 21. Abbas AK, Lichtman AH, Pillai S. Imunologia Celular e Molecular. 6a ed. Rio de Janeiro (RJ): Elsevier; 2008.

22. Veran $\mathrm{EH}$. Estudo de choque anafilático provocado pela aplicação de vacina contra a febre aftosa na espécie bovina em Santa Catarina no período de 1991 a 1998. 2000. [acesso 10 abr 2011]. Disponível em: http://www.cidasc.sc.gov.br/html/artigos/(veran)\%20 ESTUDO\%20DE\%20CHOQUE\%20ANAFIL\%C1TICO\%20 ...(VERAN).pdf

23. Omote K, Kawamata T, Nakayama Y, Yamamoto $H$, Kawamata M, Namiki A. Effects of a novel selective agonist prostaglandina receptor subtype EP4 on hiperalgesia and inflammation in monoarthtitic model. Anesthesiology. 2002;97:170-6.

24. Li A, Lao L, Wang Y, Xin J, Ren K, Berman BM, et al. Electroacupuncture activates corticotrophin-releasing hormone-containing neurons in the paraventricular nucleus of the hypothalammus to alleviate edema in a rat model of inflammation. BMC Complement Altern Med. $2008 ; 12(8): 20$.

25. Kurebayashi LFS, Gnatta JR, Borges TP, Silva MJP. Applicability of auriculotherapy in reducing stress and as a coping strategy in nursing professionals. Rev. LatinoAm. Enfermagem. 2012;20(5):980-7.

26. Cunha TM, Verri JRW, Vivancos GG, Moreira IF, Reis S, Parada CA, et al. An electronic pressure-meter nociception paw test for mice. Braz J Med Biol Res. 2004;37;401-7. 